\title{
Food insecurity among people who inject drugs in Los Angeles and San Francisco
}

\author{
Jane Schmitz ${ }^{1, *,} \dagger$, Alex H Kral ${ }^{2}$, Daniel Chu ${ }^{1}$, Lynn D Wenger ${ }^{2}$ and Ricky N Bluthenthal ${ }^{1}$ \\ ${ }^{1}$ Department of Preventive Medicine, Keck School of Medicine, University of Southern California, Los Angeles, CA, USA: \\ ${ }^{2}$ RTI International, San Francisco, CA, USA
}

Submitted 20 February 2015: Final revision received 27 January 2016: Accepted 2 February 2016: First published online 9 March 2016

\begin{abstract}
Objective: We estimated the prevalence of food insecurity among people who inject drugs (PWID) in Los Angeles and San Francisco and explored correlates of food insecurity.

Design: A cross-sectional study that measured $30 \mathrm{~d}$ food insecurity using the US Adult Food Security Survey ten-item Module developed by the US Department of Agriculture. Food insecurity was defined as including low and very low food security. Setting: Two cities in the state of California, USA.

Subjects: Male and female active PWID ( $n$ 777).

Results: Among participants, 58\% reported food insecurity and $41 \%$ reported very low food security. Food-insecure PWID were more likely to report being homeless (prevalence ratio $(P R)=1 \cdot 20 ; 95 \%$ CI 1.05, 1.37), chest pain in the past 12 months ( $\mathrm{PR}=1 \cdot 19$; CI 1.06, 1.35), acquiring syringes from someone who goes to a syringe exchange programme $(\mathrm{PR}=1.27 ; 95 \% \mathrm{CI} 1.13,1.43)$ and feeling at risk for arrest for possession of drug paraphernalia ( $\mathrm{PR}=1 \cdot 30$; $95 \% \mathrm{CI} 1 \cdot 15,1 \cdot 46)$.

Conclusions: Current food insecurity was common among PWID in these two cities, yet few factors were independently associated with food insecurity. These data suggest that broad strategies to improve food access for this high-risk population are urgently needed.
\end{abstract}

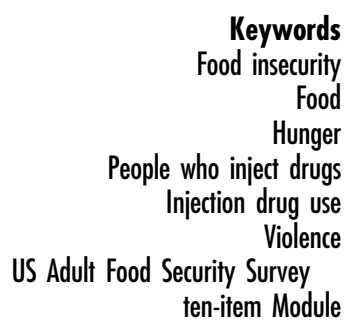

The prevalence of folod insecurity, defined as limited or uncertain availability of nutritionally adequate and safe foods or limited or uncertain ability to acquire acceptable foods in socially acceptable ways', has increased in the past decade and is concentrated in low-income households, large metropolitan centres and minority populations in the USA ${ }^{(1)}$. Similar to the US Department of Agriculture (USDA) terminology, food insecurity includes both low and very low food security. In 2012, one in fourteen adults in the USA were unable to secure dependable access to nutritious, acceptable food at some point in the previous 12 months $^{(1)}$. In California, food insecurity has increased overall from 2001 to 2009 with low-income adults experiencing the largest increase (from $8 \%$ to $17 \%)^{(2)}$.

Inadequate dietary intake impairs nutrition, which in turn weakens the immune system and increases disease susceptibility and severity ${ }^{(3)}$. Adults who are food insecure are more likely to report poor health ${ }^{(4)}$, depression ${ }^{(5)}$ and

† Correspondence address: Jane Schmitz c/o Ricky Bluthenthal, Keck School of Medicine, University of Southern California, Soto Street Building SSB, 2001 N. Soto Street - 3rd Floor - Rm 302R - MC 9239, Los Angeles, CA 90032-3628, USA. to experience delayed access to medical care, medications and hospital admissions than their food-secure peers ${ }^{(6)}$.

Food insecurity is a significant, but understudied problem among the estimated 16 million people who inject drugs (PWID) globally ${ }^{(7)}$. Studies have shown that PWID have lower body weight and impaired micronutrient status than their non-drug using peers ${ }^{(8)}$. Existing reports indicate that food insecurity is associated with depression symptoms ${ }^{(9,10)}$ and sex work and unprotected sex among HIV-positive PWID $^{(11)}$. One study found that $65 \%$ of PWID in urban Canada reported difficulty affording enough food and feeling hungry as a result ${ }^{(9)}$. However, that study relied on a single question for estimating hunger ${ }^{(9)}$, a modified measure specific to Canada ${ }^{(12)}$. Research on the vulnerable intersection between hunger and injection drug use representing areas outside North America is lacking.

In the present study, we use the US Adult Food Security Survey Module (ten item) developed by the USDA. It is a nationally validated and widely used measure that permits comparison with the general US population ${ }^{(13)}$. The primary aim of the present study was to estimate the prevalence of food insecurity among PWID in Los Angeles and San 
Francisco and explore correlates of food insecurity with sociodemographic and health indicators.

\section{Methods}

\section{Procedures}

Data are from a multi-method, cross-sectional research project investigating drug injection initiation funded by the National Institute on Drug Abuse (NIDA; grant number 1R01DA027689). Data included 777 quantitative interviews and 114 qualitative interviews with PWID in Los Angeles and San Francisco. In the current paper we report only from the quantitative survey which included participants 18 years and older. Study participants were recruited using community outreach and targeted sampling methods ${ }^{(14,15)}$. Eligible participants were 18 years of age or older and had at least one injection episode in the last $30 \mathrm{~d}$ as verified by visible signs of recent venepuncture ${ }^{(16)}$. After providing informed consent, participants completed a computer-assisted personal interview (Questionnaire Development System; NOVA Research Company, Bethesda, MD, USA) with a trained interviewer that addressed sociodemographics, drug use history, practices and patterns, drug injection initiation episode, sex risk, health-care utilization, exposure to violence, police contact and food insecurity. Participants were remunerated \$US 20 for completing the survey.

\section{Measures}

Food security in the last $30 \mathrm{~d}$ was ascertained using the US Adult Food Security Survey ten-item Module ${ }^{(1)}$. This questionnaire consists of three types of questions. The first set of questions asks how true ('never', 'sometimes', 'often') the following statements were for participants: (i) 'I worried whether my food would run out before I could get more food'; (ii) 'The food that I had just didn't last, and I wasn't able to get more food'; and (iii) 'I couldn't manage to eat balanced meals'. The second set of questions asks the following 'yes'/"no' questions: (i) 'Did you ever cut the size of your meal or skip meals because there was not enough food?'; and (ii) 'Did you ever not eat for a whole day because there wasn't enough food?'. If participants replied 'yes' to either, they were then asked on how many days in the last $30 \mathrm{~d}$ this occurred. The last set of questions requested 'yes'/no' responses to the following items: (i) 'In the last $30 \mathrm{~d}$, did you ever eat less than you felt you should eat?'; (ii) 'In the last $30 \mathrm{~d}$, were you ever hungry but didn't eat because there was not enough food?'; and (iii) 'In the last $30 \mathrm{~d}$, did you lose weight because there wasn't enough food?'

The food security scale (continuous measure) and food security status (categorical measure) were created according to USDA guidance ${ }^{(17)}$. Using responses to the questionnaire, we created a 0-10 point scale of food security where responses of 'yes' or 'sometimes' or 'often true' were counted as 1 point. For the 'number of days' items, responses of $5 \mathrm{~d}$ or more were counted as 1 point. We classified participants with three or more affirmative responses as food insecure and six or more affirmative responses as very low food security status.

Data for a wide range of other domains were also collected including socio-economic (employment, income sources, housing status, among others) and sociodemographic characteristics (age, gender, race/ethnicity, among others). We asked comprehensive questions about drug use history, current use patterns and administration routes for the following substances: alcohol, powder cocaine, crack cocaine, heroin, methamphetamine, and non-medical use of prescription opiates, stimulants, tranquilizers and sedatives, among other items. Information on injection-related and sex-related HIV risk was also gathered, as were items on common health problems among PWID such as abscess and overdose. Utilization of preventive health services (e.g. HIV testing, HCV testing) was queried as well. Lastly, we collected data on exposure to and experience of violence.

\section{Analysis}

A wide range of variables were considered as potential correlates of food insecurity. Due to the paucity of research conducted on food insecurity among PWID, we did not restrict our analysis to variables with documented associations. All bivariate analyses tested differences using the $\chi^{2}$ test or Fisher's exact test, with $P<0.05$ as the criterion for statistical significance. For the multivariate analyses, we included all variables that were statistically associated $(P<0.05)$ with food insecurity in the bivariate analyses as predictors for food insecurity. The resulting final model retained only variables with parameter estimates significant at the $P<0.05$ level. Due to the high prevalence of food insecurity, we calculated prevalence ratios (PR) using a generalized linear model with a binomial distribution and log link function. All analyses were repeated for the alternative food security score cut-off representing very low food security. All statistical analyses were computed using the statistical software package STATA version $10 \cdot 1$.

\section{Results}

Three-quarters of respondents were male and over 40 years of age. The sample was 34\% White, $30 \%$ African American, 25\% Hispanic, and 11\% Asian American, American Indian, Pacific Islander or mixed race. Socio-economic deprivation was high, with $81 \%$ reporting an income under \$US 1350/month, and 63\% reporting being currently homeless. In addition, one-third (36\%) had not completed high school. Roughly one in twelve participants reported engaging in sex work in the prior 6 months. Lastly, 30\% reported being diagnosed with 
depression and among those who reported ever being tested for HIV, $7 \%$ were HIV-positive.

\section{Food insecurity and associations of variables with food insecurity}

Over half (58\%) of the participants reported food insecurity and $41 \%$ met USDA criteria for very low food security status. A wide range of demographic, health characteristics, drug and sexual risk behaviours as well as exposure to violence were evaluated for their association with food insecurity (Tables 1 and 2). High prevalence of food insecurity did not vary by demographic variables such as age, race, ethnicity, recruitment city and gender in bivariate analysis. Although food insecurity was similar among participants with different income and education levels, it was more frequently reported among PWID who reported being homeless (62\% v. 50\%; $P=0.001)$, experiencing chest pain in the past 12 months (67\% v. 55\%; $P=0.001)$ and needing dental care in the past 6 months $(62 \% v .52 \% ; P=0.005)$.

Several variables related to drug and sexual risk behaviours were associated with food insecurity. PWID who acquired syringes from someone who goes to a syringe exchange (also referred to as indirect exchange use $\left.^{(16)}\right)$ in the past 6 months $(70 \% v .54 \% ; P<0.001)$ and those engaging in distributive syringe sharing $(75 \% v$. $54 \% ; P<0.001)$ more frequently reported food insecurity. Feeling at risk of arrest for possessing drug paraphernalia was associated with reported food insecurity ( $67 \% \mathrm{v} .50 \%$; $P<0 \cdot 001)$. Reporting poly non-injection drug use (63\% $v$. $54 \% ; P=0.013)$ in the last $30 \mathrm{~d}$ was associated with a higher prevalence of food insecurity and, among specific drugs queried, only use of goofball (a mixture of methamphetamine and heroin) in the last $30 \mathrm{~d}$ was associated with food insecurity. Those PWID reporting having any casual sex partners $(64 \% v .55 \% ; P=0.012)$ or paying (68\%v. 56\%; $P=0.019)$ sex partners in the past 6 months reported more food insecurity.

Exposure to violence as a witness or knowing about a violent attack exhibited a consistent association with food insecurity. For example, PWID who reported being punched, slapped, kicked or physically hurt in the past 12 months were more likely to be food insecure than those not reporting violence $(72 \% v .53 \% ; P<0.001)$ and those who knew someone who was raped in the past 12 months reported food insecurity more frequently than those without such knowledge (69\% v. $55 \% ; P<0.001)$.

After excluding variables that were not associated with food insecurity in bivariate or fully adjusted models, four variables were significantly associated with food insecurity (Table 3). Compared with their peers who were food secure, food-insecure PWID were more likely to be currently homeless $(\mathrm{PR}=1 \cdot 20 ; 95 \% \mathrm{CI} 1.05,1 \cdot 37)$, to report chest pain ( $\mathrm{PR}=1 \cdot 19 ; 95 \%$ CI 1.06, 1.35), to report indirect syringe exchange programme use $(\mathrm{PR}=1 \cdot 27 ; 95 \%$
CI $1.13,1.43)$ and to feel at risk for arrest for possession of drug paraphernalia ( $\mathrm{PR}=1 \cdot 30 ; 95 \%$ CI 1.15, 1.46).

\section{Discussion}

The present study found that well over half of PWID in Los Angeles and San Francisco reported being food insecure. The prevalence of food insecurity among PWID (58\%) is more than four times the level (14\%) documented among adults in the $\mathrm{USA}^{(1)}$. This level is among the highest found in any demographic sub-population in the USA as reported by the USDA (the highest level of food insecurity in a nationally representative survey was $35 \%$ in households headed by single women $)^{(1)}$. Furthermore, most PWID who were food insecure in the present study met criteria for very low food security $(71 \%, 317 / 447)$; and the absolute prevalence of very low food security in the present study ( $41 \%)$ is more than seven times higher than the prevalence of very low food security in the overall US adult population $(5 \%)^{(1)}$. Our study is consistent with previous research that found exceedingly high levels of food insecurity among people who use drugs, PWID and HIV-positive individuals, although use of alternative methods to establish food insecurity prevalence prevents making direct comparisons. In a Vancouver-based study, $64.7 \%$ of PWID self-reported to be currently hungry due to a lack of money ${ }^{(9)}$; and $54.5 \%$ of PWID in London, Ontario reported not having enough to eat because of a lack of money $^{(12)}$. Similarly, about half (53.6\%) of an HIV-positive population of adults living in poverty in San Francisco were food insecure based on the nine-question Household Food Insecurity Access Scale used primarily in international settings ${ }^{(18)}$. Despite using a range of methods to estimate food insecurity or hunger, these studies consistently describe alarmingly high levels of food insecurity among PWID in North America.

Other studies have reported that PWID often eat fewer meals or skip meals for an entire day due to binge drug use $^{(12,19)}$ and this may explain the overall high level of food insecurity in our PWID population as well. Not only is overall dietary intake lower, diet composition is often significantly different among drug users. For example, female drug users living in Hartford, Connecticut report eating at most once per day, often consuming a small amount of rice to survive during drug binges ${ }^{(20)}$. Although some drugs stimulate appetite, most drugs used described by our study participants suppress appetite. Efforts to improve food insecurity should consider unique dietary intake preferences and patterns in the PWID population. Clear patterns did not emerge as to which drugs, alone or in combination, may have a particular effect on food security status. Food insecurity was high throughout this drug-using population.

The present study suggests that housing status may increase risk of food insecurity among PWID. 
Table 1 Prevalence of food insecurity among people who inject drugs ( $n$ 777) by demographic and health characteristics, Los Angeles and San Francisco, 2011-2013

\begin{tabular}{|c|c|c|c|c|}
\hline Characteristic* $^{*}$ & No. reporting food insecurity & $\%$ & PR & $95 \% \mathrm{Cl}$ \\
\hline \multicolumn{5}{|l|}{ Gender } \\
\hline Male Ref. & $319 / 572$ & 55.8 & 1.00 & Ref. \\
\hline Female & $127 / 203$ & $62 \cdot 6$ & $1 \cdot 12$ & $0.99,1.28$ \\
\hline Intersex/hermaphrodite & $1 / 2$ & $50 \cdot 0$ & 0.90 & $0.22,3.59$ \\
\hline \multicolumn{5}{|l|}{ Age (years) } \\
\hline$<30^{\text {Ref. }}$ & $50 / 80$ & 62.5 & 1.00 & Ref. \\
\hline $30-39$ & $47 / 86$ & $54 \cdot 7$ & 0.87 & $0.68,1.13$ \\
\hline $40-49$ & $141 / 223$ & $63 \cdot 2$ & 1.01 & $0.83,1.23$ \\
\hline$\geq 50$ & $209 / 388$ & 53.9 & 0.86 & $0.71,1.05$ \\
\hline \multicolumn{5}{|l|}{ US born } \\
\hline No Ref. & $24 / 42$ & $57 \cdot 1$ & 1.00 & Ref. \\
\hline Yes & $423 / 735$ & $57 \cdot 6$ & 1.01 & $0.77,1.32$ \\
\hline \multicolumn{5}{|l|}{ City of residence } \\
\hline San Francisco Ref. & $224 / 380$ & $58 \cdot 9$ & 1.00 & Ref. \\
\hline Los Angeles & $223 / 397$ & $56 \cdot 2$ & 0.95 & $0.84,1.08$ \\
\hline \multicolumn{5}{|l|}{ Income (\$US/month) } \\
\hline$<900^{\text {Ref. }}$ & $258 / 444$ & $58 \cdot 1$ & 1.00 & Ref. \\
\hline $900-1350$ & $115 / 183$ & $62 \cdot 8$ & 1.08 & $0.94,1.24$ \\
\hline $1351-2250$ & $49 / 96$ & 51.0 & 0.88 & $0.71,1.08$ \\
\hline$>2250$ & $23 / 51$ & $45 \cdot 1$ & 0.78 & $0.57,1.06$ \\
\hline \multicolumn{5}{|c|}{ High-school education or more } \\
\hline No ${ }^{\text {Ref. }}$ & $161 / 278$ & $57 \cdot 9$ & 1.00 & Ref. \\
\hline Yes & $286 / 499$ & $57 \cdot 3$ & 0.99 & $0.87,1 \cdot 12$ \\
\hline \multicolumn{5}{|l|}{ Race/ethnicity† } \\
\hline White Ref. & $167 / 265$ & 63.0 & 1.00 & Ref. \\
\hline African American & $125 / 233$ & 53.6 & 0.85 & $0.73,0.99$ \\
\hline Hispanic & 109/192 & $56 \cdot 8$ & 0.90 & $0.77,1.05$ \\
\hline All others & $44 / 82$ & 53.7 & 0.85 & $0.68,1.06$ \\
\hline \multicolumn{5}{|l|}{ Currently homeless } \\
\hline No ${ }^{\text {Ref. }}$ & $145 / 292$ & $49 \cdot 7$ & 1.00 & Ref. \\
\hline Yes & $302 / 484$ & $62 \cdot 4$ & 1.26 & $1 \cdot 10,1.44$ \\
\hline \multicolumn{5}{|l|}{ Sexual orientation } \\
\hline Heterosexual $^{\text {Ref. }}$ & $373 / 659$ & $56 \cdot 6$ & 1.00 & Ref. \\
\hline Lesbian/gay & $16 / 33$ & 48.5 & 0.86 & $0.60,1.23$ \\
\hline Bisexual & $53 / 77$ & $68 \cdot 8$ & 1.22 & $1.03,1.43$ \\
\hline \multicolumn{5}{|l|}{ US Armed Forces } \\
\hline No Ref. & $403 / 691$ & $58 \cdot 3$ & 1.00 & Ref. \\
\hline Yes & $44 / 84$ & $52 \cdot 4$ & 0.90 & $0.73,1 \cdot 11$ \\
\hline \multicolumn{5}{|l|}{ Diagnosed depression } \\
\hline No Ref. & $301 / 544$ & $55 \cdot 3$ & 1.00 & Ref. \\
\hline Yes & $146 / 233$ & $62 \cdot 7$ & $1 \cdot 13$ & $1.00,1.28$ \\
\hline \multicolumn{5}{|l|}{ HIV-positive test result } \\
\hline No Ref. & $388 / 687$ & $56 \cdot 5$ & 1.00 & Ref. \\
\hline Yes & $35 / 53$ & $66 \cdot 0$ & $1 \cdot 17$ & $0.95,1.43$ \\
\hline \multicolumn{5}{|c|}{ Had chest pain in the past 12 months } \\
\hline No ${ }^{\text {Ref. }}$ & $320 / 587$ & 54.5 & 1.00 & Ref. \\
\hline Yes & $127 / 189$ & $67 \cdot 2$ & 1.23 & $1.09,1.4$ \\
\hline \multicolumn{5}{|c|}{ Needed dental care in the past 6 months } \\
\hline No Ref. & $185 / 355$ & $52 \cdot 1$ & 1.00 & Ref. \\
\hline Yes & $262 / 420$ & $62 \cdot 4$ & $1 \cdot 20$ & $1.06,1.36$ \\
\hline \multicolumn{5}{|l|}{ Health insurance } \\
\hline No Ref. & $165 / 274$ & $60 \cdot 2$ & 1.00 & Ref. \\
\hline Yes & $282 / 502$ & $56 \cdot 2$ & 0.93 & $0.82,1.05$ \\
\hline
\end{tabular}

PR, prevalence ratio; Ref., reference category.

*Information was missing for ten or fewer participants for all variables except HIV-positive test result $(n 37)$

t'All others' includes Asians, Pacific Islanders and Native Americans.

Previous studies support an association between food insecurity and unstable housing or homelessness ${ }^{(9,18,21,22)}$, which severely limits, if not precludes, the ability to store and prepare food. In contrast to studies that documented a positive association between income poverty and hunger, such as in a national sample of the USA ${ }^{(1)}$, in low-income households in Los Angeles County ${ }^{(21)}$ and in people living with HIV/AIDS in Canada ${ }^{(22)}$, poverty was not associated with food insecurity in our sample. However, our findings are consistent with an association between income and hunger, as the highest-income group was the least food insecure. Our study was not designed to assess incomerelated effects and statistical power was low to detect variation across income groups, as more than half of participants reported an income of less than \$US 900/ month, an amount less than the federal poverty threshold 
Table 2 Prevalence of food insecurity among people who inject drugs $(n 777)$ by drug and sexual risk behaviours and experienced and witnessed violence, Los Angeles and San Francisco, 2011-2013

\begin{tabular}{|c|c|c|c|c|}
\hline Risk behaviours* & No. reporting food insecurity & $\%$ & PR & $95 \% \mathrm{Cl}$ \\
\hline \multicolumn{5}{|l|}{ Syringe acquisition past 6 months } \\
\hline \multicolumn{5}{|l|}{ Syringe exchange } \\
\hline No Ref. & $65 / 132$ & $49 \cdot 2$ & 1.00 & Ref. \\
\hline Yes & $382 / 644$ & $59 \cdot 3$ & $1 \cdot 20$ & $1.00,1.45$ \\
\hline \multicolumn{5}{|c|}{ From someone who goes to syringe exchange } \\
\hline No ${ }^{\text {Ref. }}$ & $313 / 584$ & $53 \cdot 6$ & 1.00 & Ref. \\
\hline Yes & $134 / 192$ & 69.8 & 1.31 & $1 \cdot 16,1.48$ \\
\hline \multicolumn{5}{|c|}{ From shooting gallery or drug dealer } \\
\hline No Ref. & $388 / 692$ & $56 \cdot 1$ & 1.00 & Ref. \\
\hline Yes & $59 / 84$ & $70 \cdot 2$ & 1.25 & $1.07,1.46$ \\
\hline \multicolumn{5}{|l|}{ From unauthorized source } \\
\hline No ${ }^{\text {Ref. }}$ & $272 / 506$ & 53.8 & 1.00 & Ref. \\
\hline Yes & $175 / 270$ & $64 \cdot 8$ & 1.24 & $1 \cdot 10,1.39$ \\
\hline \multicolumn{5}{|l|}{ Syringe use } \\
\hline \multicolumn{5}{|l|}{ Distributive syringe sharing } \\
\hline No Ref. & $361 / 663$ & 54.4 & 1.00 & Ref. \\
\hline Yes & $86 / 114$ & $75 \cdot 4$ & 1.39 & $1.22,1.57$ \\
\hline \multicolumn{5}{|l|}{ Receptive syringe sharing } \\
\hline No Ref. & $369 / 671$ & $55 \cdot 0$ & 1.00 & Ref. \\
\hline Yes & 78/106 & 73.6 & 1.34 & $1.17,1.53$ \\
\hline \multicolumn{5}{|c|}{ Injected by another person in the past $30 \mathrm{~d}$} \\
\hline No ${ }^{\text {Ref. }}$. & $323 / 594$ & 54.4 & 1.00 & Ref. \\
\hline Yes & $124 / 182$ & $68 \cdot 1$ & 1.25 & $1.11,1.42$ \\
\hline \multicolumn{5}{|l|}{ Drug use in the past $30 \mathrm{~d}$} \\
\hline \multicolumn{5}{|l|}{ Poly injected drug use } \\
\hline Only one drug injected ${ }^{\text {Ref. }}$ & $268 / 487$ & $55 \cdot 0$ & 1.00 & Ref. \\
\hline Two or more drugs injected & $179 / 290$ & 61.7 & $1 \cdot 12$ & $0.99,1.27$ \\
\hline \multicolumn{5}{|l|}{ Poly non-injection drug use } \\
\hline One drug or fewer used ${ }^{\text {Ref. }}$ & $251 / 465$ & $54 \cdot 0$ & 1.00 & Ref. \\
\hline Two or more drugs used & $196 / 312$ & $62 \cdot 8$ & $1 \cdot 16$ & $1.03,1.31$ \\
\hline Methamphetamine use & & & & \\
\hline No Ref. & $241 / 436$ & $55 \cdot 2$ & 1.00 & Ref. \\
\hline Yes & $206 / 341$ & $60 \cdot 4$ & 1.07 & $0.95,1.21$ \\
\hline Heroin use & & & & \\
\hline No Ref. & $91 / 157$ & 58.0 & 1.00 & Ref. \\
\hline Yes & $356 / 620$ & 57.4 & 0.99 & $0.86,1 \cdot 15$ \\
\hline Crack use & & & & \\
\hline No Ref. & $233 / 434$ & 53.7 & 1.00 & Ref. \\
\hline Yes & $214 / 343$ & $62 \cdot 4$ & 1.12 & $0.94,1.34$ \\
\hline Speedball† use & & & & \\
\hline No Ref. & $368 / 646$ & $57 \cdot 0$ & 1.00 & Ref. \\
\hline Yes & $79 / 131$ & $60 \cdot 3$ & 1.07 & $0.92,1.25$ \\
\hline Goofball† use & & & & \\
\hline No Ref. & $381 / 682$ & $55 \cdot 9$ & 1.00 & Ref. \\
\hline Yes & 66/95 & 69.5 & 1.27 & $1.10,1.47$ \\
\hline Opiate prescription use & & & & \\
\hline No Ret. & $295 / 532$ & 55.5 & 1.00 & Ref. \\
\hline Yes & $152 / 245$ & $62 \cdot 0$ & 1.12 & $0.99,1.27$ \\
\hline Tranquilizer prescription use & & & & \\
\hline No Ref. & $325 / 583$ & $55 \cdot 8$ & 1.00 & Ref. \\
\hline Yes & $122 / 194$ & 62.9 & $1 \cdot 13$ & $0.99,1.28$ \\
\hline Marijuana use & & & & \\
\hline No Ref. & $173 / 304$ & $56 \cdot 9$ & 1.00 & Ref. \\
\hline Yes & $248 / 419$ & $59 \cdot 2$ & 1.04 & $0.92,1.18$ \\
\hline Frequency of injection drug us & & & & \\
\hline $1-29^{\text {Ref. }}$ & $211 / 362$ & $58 \cdot 3$ & 1.00 & Ref. \\
\hline $30-89$ & $122 / 214$ & $57 \cdot 0$ & 0.98 & $0.85,1.13$ \\
\hline$\geq 90$ & $114 / 201$ & $56 \cdot 7$ & 0.97 & $0.84,1.13$ \\
\hline Fear of law enforcement & & & & \\
\hline Feels at risk for arrest for drug & & & & \\
\hline No ${ }^{\text {Ref. }}$ & $216 / 432$ & $50 \cdot 0$ & 1.00 & Ref. \\
\hline Yes & $231 / 344$ & $67 \cdot 2$ & 1.34 & $1.19,1.51$ \\
\hline Sexual behaviour in the past $6 n$ & & & & \\
\hline Casual sex partner & & & & \\
\hline No Ref. & $296 / 541$ & 54.7 & 1.00 & Ref. \\
\hline Yes & $151 / 236$ & $64 \cdot 0$ & 1.17 & $1.03,1.32$ \\
\hline Paying sex partner & & & & \\
\hline No Ref. & $386 / 687$ & $56 \cdot 2$ & 1.00 & Ref. \\
\hline Yes & $61 / 90$ & $67 \cdot 8$ & 1.21 & $1.03,1.41$ \\
\hline
\end{tabular}


Table 2 Continued

\begin{tabular}{|c|c|c|c|c|}
\hline Risk behaviours* & No. reporting food insecurity & $\%$ & PR & $95 \% \mathrm{Cl}$ \\
\hline \multicolumn{5}{|c|}{ Experienced violence in the past 12 months } \\
\hline \multicolumn{5}{|c|}{ Threatened with a knife, gun or weapon } \\
\hline No Ref. & $308 / 561$ & 54.9 & 1.00 & Ref. \\
\hline Yes & $137 / 211$ & 64.9 & $1 \cdot 18$ & $1.04,1.34$ \\
\hline \multicolumn{5}{|c|}{ Punched, slapped, kicked or physically hurt } \\
\hline No Ref. & $305 / 576$ & $53 \cdot 0$ & 1.00 & Ref. \\
\hline Yes & $142 / 198$ & 71.7 & 1.35 & $1.21,1.52$ \\
\hline \multicolumn{5}{|c|}{ Had a gun, knife or weapon used against you } \\
\hline No Rer. & $357 / 645$ & $55 \cdot 3$ & 1.00 & Ref. \\
\hline Yes & $88 / 127$ & $69 \cdot 3$ & 1.25 & $1.09,1.43$ \\
\hline \multicolumn{5}{|c|}{ Stranger attacked you on the street } \\
\hline No Ref. & $323 / 602$ & 53.7 & 1.00 & Ref. \\
\hline Yes & $124 / 173$ & $71 \cdot 7$ & $1 \cdot 34$ & $1.19,1.51$ \\
\hline \multicolumn{5}{|c|}{ Had physical force or threats of force to make you have vaginal sex, anal sex or oral sex } \\
\hline No Ref. & $425 / 750$ & 56.7 & 1.00 & Ref. \\
\hline Yes & $22 / 24$ & $91 \cdot 7$ & 1.62 & $1.41,1.85$ \\
\hline \multicolumn{5}{|c|}{ Witnessed violence in the past 12 months } \\
\hline \multicolumn{5}{|c|}{ Saw someone shot at, but not hit } \\
\hline No Ref. & $342 / 611$ & $56 \cdot 0$ & 1.00 & Ref. \\
\hline Yes & $105 / 160$ & $65 \cdot 6$ & $1 \cdot 17$ & $1.03,1.34$ \\
\hline \multicolumn{5}{|c|}{ Knew someone who was shot } \\
\hline No Ref. & $305 / 551$ & 55.4 & 1.00 & Ref. \\
\hline \multirow{2}{*}{\multicolumn{5}{|c|}{ Knew someone who was killed }} \\
\hline & & & & \\
\hline No Ref. & $246 / 455$ & $54 \cdot 1$ & 1.00 & Ref. \\
\hline Yes & $201 / 318$ & $63 \cdot 2$ & 1.17 & $1.04,1.32$ \\
\hline \multicolumn{5}{|c|}{ Knew someone who killed themselves } \\
\hline No Ref. & $348 / 630$ & $55 \cdot 2$ & 1.00 & Ref. \\
\hline Yes & $96 / 139$ & $69 \cdot 1$ & 1.25 & $1 \cdot 1,1.43$ \\
\hline \multicolumn{5}{|c|}{ Knew someone who had been raped } \\
\hline No ${ }^{\text {Ref. }}$ & $341 / 622$ & $54 \cdot 8$ & 1.00 & Ref. \\
\hline Yes & $104 / 150$ & $69 \cdot 3$ & $1 \cdot 26$ & $1.11,1.44$ \\
\hline
\end{tabular}

PR, prevalence ratio; Ref., reference category.

*Information missing for ten or fewer participants for all variables.

†Speedball is a mixture of heroin and cocaine; goofball is a mixture of methamphetamine and heroin.

Table 3 Characteristics and behaviours independently associated with food insecurity among people who inject drugs in multivariate analysis ( $n$ 775), Los Angeles and San Francisco, 2011-2013

\begin{tabular}{|c|c|c|}
\hline Characteristic or behaviour & aPR & $95 \% \mathrm{Cl}$ \\
\hline Currently homeless & 1.20 & $1.05,1.37$ \\
\hline Chest pain in the past 12 months & 1.19 & $1.06,1.35$ \\
\hline $\begin{array}{l}\text { Acquiring syringes from someone who goes to a } \\
\text { syringe exchange }\end{array}$ & $1 \cdot 27$ & $1.13,1.43$ \\
\hline $\begin{array}{l}\text { Feeling at risk for arrest for possession of drug } \\
\text { paraphernalia }\end{array}$ & 1.30 & $1.15,1.46$ \\
\hline
\end{tabular}

aPR, adjusted prevalence ratio.

of \$US 995/month ${ }^{(23)}$; and only forty-nine people (less than $9 \%$ of the sample) reported an income above \$US 2250/month.

The similarity in prevalence of food insecurity among PWID in Los Angeles and San Francisco (56.2\% and $58.9 \%$, respectively) is striking, given that PWID in each city may have access to a very different array of services and resources. The similar prevalence of food insecurity in the two cities strengthens the case for the generalizability of our findings to other urban areas of the USA; and suggests that the current range of services in either city is insufficient to address hunger among PWID.
Fear of arrest for possession of drug paraphernalia was significantly associated with food insecurity, even after adjustment for other factors. Interaction with law enforcement has been found to influence injection risk among PWID ${ }^{(24-26)}$. Syringe sharing among injection drug users was found to be more common among those who feel at risk for arrest for possession of drug paraphernalia $^{(24)}$. Syringe use variables displayed consistent associations with food insecurity in bivariate analysis but not in multivariate analysis. In the adjusted, final model we found that only indirect syringe exchange use was associated with food insecurity. A Canadian study found associations of unsafe injection practices with food insecurity ${ }^{(12)}$. It is possible that not directly using syringe exchange services and concern with arrest for drug paraphernalia indicated an elevated fear of exposure as a PWID. This fear of exposure could also impair use of food distribution centres. More research on how and why food insecurity is associated with injection-related risk and preventive service utilization is needed.

Among candidate health-related variables, only reporting chest pain in the past 12 months was associated with food insecurity in the multivariate model. Reported chest pain can be an indication of a serious health 
condition or a drug reaction among PWID. Myocardial infarction, pulmonary embolism, pneumonia and endocarditis are all more common among PWID than in the general population and can result in chest pain ${ }^{(27,28)}$. Less serious conditions that often result in chest pain include gastrointestinal reflux disease and anxiety (e.g. panic attacks). The observed association could be due to these conditions or be spurious. Previous evidence from North America supports a relationship between HIV and two behaviours related to increased risk of HIV such as needle sharing ${ }^{(12)}$ and food insecurity ${ }^{(18)}$, but evidence for such an association was lacking among our participants. Perhaps PWID who tested positive for HIV in our study sample had access to a stronger network of support services than HIV-negative PWID, such as those provided by the US federal law Ryan White CARE Act, and that contributed to a lower prevalence of food insecurity.

Violence was common in the lives of PWID in our study; $41 \%$ of participants reported direct experience of physical or sexual violence in their lives in the past 12 months. This level is likely typical among illicit substance users. For example, among a group of women and men in substance abuse treatment, 32\% reported involvement in an incident of physical violence in the previous $90 \mathrm{~d}^{(29)}$. Although violence variables were consistently associated with food insecurity in bivariate analysis, they were not significant in the final multivariate model for food security. However, one of the violencerelated variables (reported attack by a stranger) remained strongly associated with the more severe outcome of very low food security $(\mathrm{PR}=1.43, P<0.001)$. Studies have found violence exposure and food insecurity to be related $^{(30,31)}$. In another study, violence was associated with food insecurity in a large national study of women ${ }^{(32)}$. To our knowledge, we are the first to report on associations between food insecurity and exposure to violence among PWID.

Food insecurity, being homeless, interactions with and feelings about law enforcement, syringe use and exposure to violence may represent important indicators of otherwise unmeasured vulnerability and instability among PWID. Inclusion of food security questions in longitudinal studies and intervention trials among PWID would help to clarify the causal relationships between these types of variables and hunger, and inclusion of more targeted measures of life chaos or vulnerability ${ }^{(33)}$ may address unmeasured confounding. In the meantime, routine assessment of syringe-related behaviours, exposure to violence and food insecurity among PWID may help to identify subgroups at particularly elevated risk of hunger and acquisition of blood-borne infections such as hepatitis $\mathrm{C}$ virus and HIV. Given the high levels of food insecurity in this population with likely distinct dietary intake patterns, future research on this topic should probe in more depth into eating patterns, nutritional intake and anthropometric measurements.
To our knowledge this is the first time that the US Adult Food Security Survey Module has been used to quantify food insecurity among PWID in North America. The use of this survey enhances the ability to compare our findings with national prevalence estimates. The range of potential exposures assessed enabled a thorough investigation of the dynamics of food insecurity among PWID. There are possible limitations of our study. Although the US Adult Food Security Survey Module has proved to be a robust measure in many populations ${ }^{(17)}$, it has not been validated in an urban population of PWID and therefore may not be valid. Our cross-sectional data are insufficient to establish causal relationships, and our data rely on participant responses and as such are susceptible to recall, social desirability and other biases inherent in self-reported survey data ${ }^{(34)}$.

In summary, food insecurity among PWID living in Los Angeles and San Francisco is shockingly common. Few risk factors were associated with food insecurity in this sample, even though food insecurity was lowest among those reporting the highest monthly income. The absolute prevalence of food insecurity in the highest income group was still $41.5 \%$, comparable to the highest rate among any subgroup reported for the USA. Efforts to ameliorate hunger among PWID may not require refined targeting of interventions to specific subgroups, as the majority of PWID appear to be at substantial risk. Involving harm reduction programmes in food distribution could yield substantial benefits ${ }^{(35)}$; however, these programmes tend to be poorly funded ${ }^{(36)}$. Collaboration with food distribution organizations would probably be welcomed given the food insecurity prevalence in this population ${ }^{(37)}$ and the historic interest of needle exchange programmes in collaborating with other agencies ${ }^{(38)}$. Food insecurity among PWID represents an acute emergency that requires broad and urgent strategies aimed at improving food access among all PWID.

\section{Acknowledgements}

Acknowledgements: The authors thank the participants who took part in this study. The following research staff and volunteers also contributed to the study and are acknowledged here: Sonya Arreola, Vahak Bairamian, Philippe Bourgois, Soo Jin Byun, Jose Collazo, Jacob Curry, David-Preston Dent, Karina Dominguez, Jahaira Fajardo, Richard Hamilton, Frank Levels, Luis Maldonado, Askia Muhammad, Brett Mendenhall, Stephanie Dyal-Pitts and Michele Thorsen. Financial support: The research was supported by NIDA (grant number R01DA027689; Program Official, Elizabeth Lambert) and in part by the National Cancer Institute (grant number P30CA014089). The content is solely the responsibility of the authors and does not necessarily represent the official views of the National Institutes of Health. The National Institutes of 
Health had no role in the design, analysis or writing of this article. Conflict of interest: None. Authorship: J.S. analysed the data and wrote the manuscript. A.H.K. conceived of the study, contributed to data analysis and edited the manuscript. D.C. and L.D.W. contributed to data collection and editing the manuscript. R.N.B. conceived of the study, analysed the data, and contributed to writing and editing the manuscript. Ethics of human subject participation: This study was conducted according to the guidelines laid down in the Declaration of Helsinki and all procedures involving human subjects were approved by the Institutional Review Boards of the University of Southern California and RTI International. Written informed consent was obtained from all subjects.

\section{References}

1. Coleman-Jensen A, Nord M \& Singh A (2013) Household Food Security in the United States in 2012. Economic Research Report no. ERR-155. Washington, DC: US Department of Agriculture, Ecconomic Research Service.

2. Chaparro MP, Langellier B, Birnbach K et al. (2012) Nearly Four Million Californians are Food Insecure. Los Angeles, CA: UCLA Center for Health Policy Research.

3. Scrimshaw NS \& SanGiovanni JP (1997) Synergism of nutrition, infection, and immunity: an overview. Am J Clin Nutr 66, issue 2, 464S-477S.

4. Stuff JE, Casey PH, Szeto KL et al. (2004) Household food insecurity is associated with adult health status. J Nutr 134, 2330-2335

5. Palar K, Kushel M, Frongillo EA et al. (2015) Food insecurity is longitudinally associated with depressive symptoms among homeless and marginally-housed individuals living with HIV. AIDS Behav 19, 1527-1534.

6. Kushel MB, Gupta R, Gee L et al. (2006) Housing instability and food insecurity as barriers to health care among low-income Americans. J Gen Intern Med 21, 71-77.

7. Mathers BM, Degenhardt L, Phillips B et al. (2008) Global epidemiology of injecting drug use and HIV among people who inject drugs: a systematic review. Lancet 372, 1733-1745.

8. Hendricks K \& Gorbach S (2009) Nutrition issues in chronic drug users living with HIV infection. Addict Sci Clin Pract 5 , $16-23$.

9. Anema A, Wood E, Weiser SD et al. (2010) Hunger and associated harms among injection drug users in an urban Canadian setting. Subst Abuse Treat Prev Policy 5, 20.

10. Vogenthaler NS, Hadley C, Rodriguez AE et al. (2011) Depressive symptoms and food insufficiency among HIV-infected crack users in Atlanta and Miami. AIDS Behav 15, 1520-1526.

11. Shannon K, Kerr T, Milloy MJ et al. (2011) Severe food insecurity is associated with elevated unprotected sex among HIV-seropositive injection drug users independent of HAART use. AIDS 25, 2037-2042.

12. Strike C, Rudzinski K, Patterson J et al. (2012) Frequent food insecurity among injection drug users: correlates and concerns. BMC Public Health 12, 1058.

13. National Research Council (2006) Food Insecurity and Hunger in the United States: An Assessment of the Measure. Washington, DC: National Academy of Science.

14. Watters J \& Biernacki P (1989) Targeted sampling: options for the study of hidden populations. Soc Probl 36 , 416-430.
15. Bluthenthal RN \& Watters JK (1995) Multimethod research from targeted sampling to HIV risk environments. NIDA Res Monogr 157, 212-230.

16. Green TC, Bluthenthal RN, Singer M et al. (2010) Prevalence and predictors of transitions to and away from syringe exchange use over time in 3 US cities with varied syringe dispensing policies. Drug Alcohol Depend 111, 74-81.

17. Bickel G, Nord M, Price C et al. (2000) Guide to Measuring Household Food Security. Alexandria, VA: US Department of Agriculture, Food and Nutrition Service.

18. Weiser SD, Bangsberg DR, Kegeles S et al. (2009) Food insecurity among homeless and marginally housed individuals living with HIV/AIDS in San Francisco. AIDS Behav 13, 841-848.

19. Himmelgreen DA, Perez-Escamilla R, Segura-Millan S et al. (1998) A comparison of the nutritional status and food security of drug-using and non-drug-using Hispanic women in Hartford, Connecticut. Am J Phys Anthropol 107, 351-361.

20. Romero-Daza N, Himmelgreen DA, Perez-Escamilla R et al. (1999) Food habits of drug-using Peurto Rican women in inner-city Hartford. Med Anthropol 18, 281-298.

21. Furness BW, Simon PA, Wold CM et al. (2004) Prevalence and predictors of food insecurity among low-income households in Los Angeles County. Public Health Nutr 7, 791-794.

22. Normen L, Chan K, Braitstein P et al. (2005) Food insecurity and hunger are prevalent among HIV-positive individuals in British Columbia, Canada. J Nutr 135, 820-825.

23. US Census Bureau (2013) Poverty: Poverty thresholds by Size of Family and Number of Children. https://www.census. gov/hhes/www/poverty/data/threshld/ (accessed February 2016).

24. Wagner KD, Simon-Freeman R \& Bluthenthal RN (2013) The association between law enforcement encounters and syringe sharing among IDUs on skid row: a mixed methods analysis. AIDS Behav 17, 2637-2643.

25. Bluthenthal RN, Kral AH, Erringer EA et al. (1999) Drug paraphernalia laws and injection-related infectious disease risk among drug injectors. J Drug Issues 29, 1-16.

26. Bluthenthal RN, Lorvick J, Kral AH et al. (1999) Collateral damage in the war on drugs: HIV risk behaviors among injection drug users. Int J Drug Policy 10, 25-38.

27. Karpel JP (2013) Overview of pulmonary disease in injection drug users. http://www.uptodate.com/contents/overview-ofpulmonary-disease-in-injection-drug-users (accessed February 2016).

28. McCord J, Jneid H, Hollander JE et al. (2008) Management of cocaine-associated chest pain and myocardial infarction: a scientific statement from the American Heart Association Acute Cardiac Care Committee of the Council on Clinical Cardiology. Circulation 117, 1897-1907.

29. Chermack ST \& Blow FC (2002) Violence among individuals in substance abuse treatment: the role of alcohol and cocaine consumption. Drug Alcohol Depend 66, 29-37.

30. Chilton M \& Booth S (2007) Hunger of the body and hunger of the mind: African American women's perceptions of food insecurity, health and violence. J Nutr Educ Behav 39, $116-125$

31. Chilton MM, Rabinowich JR \& Woolf NH (2014) Very low food security in the USA is linked with exposure to violence. Public Health Nutr 17, 73-82.

32. Montgomery BE, Rompalo A, Hughes J et al. (2015) Violence against women in selected areas of the United States. Am J Public Health 105, 2156-2166.

33. Wong MD, Sarkisian CA, Davis C et al. (2007) The association between life chaos, health care use, and health status among HIV-infected persons. J Gen Intern Med 22, $1286-1291$. 
34. Aday LA \& Cornelius LJ (2006) Designing and Conducting Health Surveys: A Comprehensive Guide, 3rd ed. San Francisco, CA: Jossey-Bass.

35. Riley ED, Vlahov D, Huettner S et al. (2002) Characteristics of injection drug users who utilize tuberculosis services at sites of the Baltimore city needle exchange program. $J$ Urban Health 79, 113-127.

36. Bluthenthal RN, Heinzerling KG, Anderson R et al. (2008) Approval of syringe exchange programs in California: results from a local approach to HIV prevention. Am J Public Health 98, 278-283.

37. Parker J, Jackson L, Dykeman M et al. (2012) Access to harm reduction services in Atlantic Canada: implications for non-urban residents who inject drugs. Health Place 18, 152-162.

38. Centers for Disease Control and Prevention (2010) Syringe exchange programs - United States, 2008. MMWR Morb Mortal Wkly Rep 59, 1488-1491. 